BULLETIN Bulletin hispanique

HISPANIQUE Université Michel de Montaigne Bordeaux

120-1 | 2018

Varia

\title{
Góngora en los orígenes de la poesía brasileña
}

el caso de Gregório de Matos

Gongora aux origines de la poésie brésilienne : le cas de Gregório de Matos

Gongora at the root of Bresilian poetry: Gregório de Matos' case

\section{Antonio Carreira}

\section{(QpenEdition}

Journals

Edición electrónica

URL: https://journals.openedition.org/bulletinhispanique/5267

DOI: 10.4000/bulletinhispanique.5267

ISSN: 1775-3821

Editor

Presses universitaires de Bordeaux

Edición impresa

Fecha de publicación: 30 junio 2018

Paginación: 11-26

ISBN: 979-10-300-0298-0

ISSN: 0007-4640

Referencia electrónica

Antonio Carreira, «Góngora en los orígenes de la poesía brasileña», Bulletin hispanique [En línea], 120-1 | 2018, Publicado el 01 enero 2022, consultado el 08 enero 2022. URL: http://journals.openedition.org/ bulletinhispanique/5267 ; DOI: https://doi.org/10.4000/bulletinhispanique.5267 


\title{
Góngora en los orígenes de la poesía brasileńa: el caso de Gregório de Matos
}

\author{
Antonio Carreira \\ CECE (Centro para la Edición de los Clásicos Españoles)
}

Traces de Góngora dans l'œuvre poétique attribuée à Gregório de Matos Guerra (1636-1695), poète de Bahia, contemporain de Sor Juana Inés de la Cruz, qui vécut une partie de sa vie au Portugal et qui, comme Sor Juana, lut avec délectation et profit les grands poètes espagnols, en particulier Góngora et Quevedo, non sans incidences polémiques.

Mots-clés: Gongora, origines de la poésie brésilienne, Gregório de Matos, traduction et recréation.

Huellas de Góngora en la obra poética atribuida a Gregório de Matos Guerra (16361695), poeta bahiano contemporáneo de sor Juana Inés de la Cruz, que vivió parte de su vida en Portugal y, como sor Juana, leyó con fruición y provecho a los grandes poetas castellanos, en especial Góngora y Quevedo, lo que generó cierta polémica.

Palabras clave: Góngora, orígenes de la poesía brasileña, Gregório de Matos, traducción y recreación.

Abstract: We will study the tracks of Gongora in the poetical work attributed to Gregório de Matos Guerra (1636-1695). The poet from Bahia, contemporary from Sor Juana Inés de la Cruz, spent a part of his life in Portugal and, like Sor Juana, read with delight and advantage the great Spanish poets, Gongora as Quevedo in particular — not without some polemical effect.

Keywords: Gongora, origin of Brasilian poetry, Gregório de Matos, translation and re-creation. 
José Ares Montes, in memoriam

Gregório de Matos es un poeta casi desconocido en el ámbito hispano, a pesar de que sus obras llevan un siglo editadas y su bibliografía crece sin cesar. Ares, en su libro sobre Góngora y la poesía portuguesa del siglo XVII, lo menciona solo dos veces, una de ellas en nota bis, junto con los otros poetas brasileños coetáneos suyos, Bernardo Vieira (hermano de António, el gran predicador) y Botelho de Carvalho, de quienes Ares se ocupa más largamente ${ }^{1}$. Es obvio que no pudo consultar las Obras de Matos en la edición de Afrânio Peixoto impresa en Río de Janeiro, 1923-1933 (6 vols.), porque de lo contrario no se hubiera limitado a estudiar un soneto, que confiesa haber tomado de la Antologia dos Poetas Brasileiros da Fase Colonial, de Sérgio Buarque de Hollanda (p. 340), ni habría podido afirmar que Matos es un simple traductor de Góngora (p. 110). Pero a Matos tampoco se le prestó atención en su país hasta la segunda mitad del s. XX, de hecho, los críticos han denunciado el secuestro de su figura en la historia literaria. Haroldo de Campos lo dice estableciendo interesantes paralelos:

O caso Gregório, enquanto hiato no horizonte recepcional, näo difere fundamentalmente do caso Góngora na Espanha; do caso (ainda irresolvido e sem resgate) do Barroco portugués; dos casos Caviedes e Hernando Dominguez Camargo na América Hispânica, para ficar nesses exemplos de todo em todo expressivos. ${ }^{2}$

Sigue hablando de la gongorofobia, que en Portugal y colonias produjo esa especie de repulsión, visible aun en nuestros días, hacia la literatura del s. XVII, que arrincona los mejores poetas portugueses posteriores a Camóes, $\mathrm{y}$ en Brasil ningunea la literatura anterior al romanticismo. Las razones para tal fenómeno son complejas, y una sobresale: Matos es un poeta goliardesco o carnavalesco, sin pelos en la lengua, que dispara contra todo lo que se mueve y toca temas considerados tabú por la sociedad intelectual, hasta el punto de haber sido censurado por su primer editor. No vamos a entrar en la controversia sobre el asunto, porque nuestra intención ahora, mucho más modesta, se reduce a estudiar la influencia de Góngora en la obra que se atribuye a Matos, según la edición publicada por James Amado en 1969 y reimpresa en 19903. Una edición razonable que plantea otros problemas ecdóticos en que tampoco podemos meternos. Amado manejó 17 códices de la poesía matosiana en 24 volúmenes, ninguno autógrafo, de los cuales el más

1. José Ares Montes, Góngora y la poesía portuguesa del siglo XVII, Madrid: Gredos, 1956.

2. Haroldo de Campos, $O$ sequestro do barroco na formação da literatura brasileira: o caso Gregório de Mattos (Salvador, Bahia: Fundação Casa de Jorge Amado, 1989), p. 52.

3. Gregório de Matos, Obra poética, ed. de James Amado, preparação e notas de Emanuel Araújo, Rio de Janeiro: Record, 1990, 2 vols. que suman 1333 pp. 
importante es el llamado Pereira Rabelo, formado hacia 1740, que perteneció a Eugenio Asensio; posteriormente han aparecido otros hasta sumar 23 códices en 34 volúmenes, todos del s. XVIII; no contamos los del XIX ni tampoco los cancioneros parciales ${ }^{4}$. Para nuestro propósito es irrelevante que algunos poemas sean de dudosa autoría; si tienen la impronta gongorina, eso basta para probar la presencia de Góngora en el entorno donde se gestó la obra de Matos, ya que los guiños se hacen para que sean percibidos. Al fin y al cabo, las atribuciones son libres, y de ellas, a falta de otros factores, el criterio con más peso es el numérico. Amado proporciona la lista de códices en que se encuentra cada poema (pp. 1313-1332), lo que permite vislumbrar su grado de aceptación o de difusión. Recordemos, por último, que en la Bahía de la segunda mitad del s. XVII, aunque era capital de la colonia (y lo siguió siendo hasta 1763), no había imprentas, y probablemente tampoco muchos lectores; la transmisión de esta obra, reducida a la oralidad y a los apógrafos, es, pues, más precaria que la habitual entonces en los países desarrollados.

Todavía son inexcusables dos palabras sobre la vida del poeta, porque James Amado, novelista como su hermano Jorge, en la Foto proibida há 300 anos, que puso al frente de su edición de Matos, termina con una página desconcertante, en que $o$ Boca do Inferno, ataviado con una chaqueta de plástico amarillo y empuñando una guitarra eléctrica, sube a un palco en Sáo Paulo y se pone a cantar ante miles de jóvenes, micrófonos y cámaras de televisión. Dejemos a un lado al fabulador para seguir al biógrafo más seguro del poeta, Fernando da Rocha Peres. Gregório de Matos Guerra nació en Bahia en 1636, tercer hijo de un hidalgo portugués homónimo suyo, dueño de un trapiche en que trabajaba multitud de esclavos. Educado por los jesuitas, en 1650, cumplidos los 14 años, viajó a Coímbra, en cuya universidad estudió Derecho Civil y Canónico hasta licenciarse o doctorarse. Vivió treinta años en Lisboa, desempeñó cargos públicos, tuvo una hija natural y casó con su primera mujer, de quien enviudó en 1678. Hacia 1682 regresó a Bahía, de cuyo arzobispado fue vicario y tesorero. Vivió en esa ciudad unos 12 años, y allí casó por segunda vez con una mujer humilde, que le dio un hijo. Sus sátiras circulan y se celebran; finalmente por ellas es amenazado de muerte, y unos amigos consiguen ponerlo a salvo enviándolo a Luanda, capital de Angola, donde apenas escribe. Parece ser que en 1694 contribuyó al fracaso de cierta rebelión contra el gobernador de aquella colonia, quien lo devuelve a Brasil, esta vez a Pernambuco. Su muerte,

4. Gilberto Mendonça Teles, en su ed. de Matos (Se souberas falar também falaras. Antología poética, Lisboa: Imprensa Nacional-Casa da Moeda, 1989, p. 13), aporta cuatro nuevos de bibliotecas portuguesas: uno propiedad de Jorge José da Cunha (denominado Z); el códice 50I-2 de la Biblioteca da Ajuda (Z-1); el 675 de la Bibl. Municipal de Porto (Z-2); y el 3576 de la Bibl. Nac. de Lisboa (Z-3). El romance que publica en p. 397 como inédito, se encuentra en la ed. de J. Amado, p. 798. Sobre esta cuestión la mejor puesta al día es el trabajo de Silvia La Regina, «Per un'edizione critica di Gregório de Matos», Maria José de Lancastre, Silvano Peloso y Ugo Serani (eds.), E vós, Tágides minhas. Miscellanea in onore di Luciana Stegagno Picchio (Viareggio-Lucca: Mauro Baroni, 1999), pp. 405-413. Véase también su contribución al libro citado en la nota siguiente, "Os códices de Gregório de Mattos», pp. 33-53. 
debida a fiebres contraídas en África, acaeció en Recife en 1695: la versión piadosa habla de una agonía larga y contrita; otra más severa, procedente de un fraile, dice que murió como impíos.

Según lo presentan los documentos, Matos no es ningún cantautor o buscador de celebridad fácil, sino un abogado competente, de familia bien relacionada con la Inquisición, que en ratos libres o en reuniones de amigos empuña su viola de calabaza, y da rienda suelta a sus sentimientos religiosos, o a sus ocurrencias eróticas y políticas. La segunda sección de su obra, tal como la organiza Amado, empieza con una Salve Rainha que es, en efecto, una glosa de la Salve en 23 redondillas; siguen sonetos a la Virgen, al niño Jesús, a Cristo crucificado, romances que sirven de acto de contrición o de meditación antes de comulgar, un diálogo en décimas entre el alma y el demonio, otros poemas a la Concepción, a san Antonio, y varias glosas de motes. En todo ello despliega los recursos propios del conceptismo sacro, y no hay nada que los distinga salvo la destreza, y menos algo que haga dudar de su sinceridad. Si de aquí pasamos a la cara erótica de esta poesía, toparemos con un autor para quien el sexo no es algo pecaminoso en grado sumo, sino un tema normal y corriente, del que se puede hablar en verso igual que en prosa, con la misma naturalidad que lo hicieron, por ejemplo, Marcial o Petronio en una cultura anterior al cristianismo. Un buen ejemplo es el poema "Ei-lo vai desenfreado» (p. 894), dedicado a umas freyras que mandáram perguntar por ociosidade ao poeta a difinição do príapo, es decir, del miembro masculino. Matos les respondió con un poema en 13 décimas tan llenas de procacidad como de ingenio. Y no es el único dedicado al asunto: el que comienza «Com cachopinha de gusto» (p. 963) hace algo similar glosando en cuatro décimas un mote muy explícito. Por el estilo son «O homem máis a mulher» (p. 981) y otros muchos. El deleite de aquellas monjas curiosas es solo comparable al espanto de algunos eruditos modernos que tras asomarse a los códices optaron por dejarlos reposar. El lector de hoy al principio se sorprende, pero en seguida sospecha que lo anómalo acaso esté en nuestra cultura, no en la de Matos, que en aquella ciudad, mezclada con razas de todas procedencias, veía normal perseguir blancas, negras, mulatas, catufas, tupíes, monjas o seglares, libres o esclavas, y que ellas respondieran como y cuando mejor les convenía. La inmoralidad, en resumen, para Matos no reside en el sexo sino en otras cosas; casi podría decirse que, de las dos caras de la moneda colonial, la erótica es la más amable. Para comprenderlo, basta leer sus descripciones de Bahía, resumidas en este breve mote que no tolera traducción: "De dous ff se compóe / esta cidade a meu ver: / um furtar, outro foder", mote que, por si fuera poco expresivo, se glosa en tres décimas (p. 38). Naturalmente, con la obra poética de Matos sucede lo mismo que con la de tantos otros poetas: no hay forma de ponerla en orden cronológico, si se exceptúan algunos textos de circunstancias. Es tan solo construcción moderna la que puede llevarnos a creer que Matos fue y escribió primero así, luego asá. No hay más fundamento para

5. Fernando da Rocha Peres \& Sílvia La Regina, Um códice setecentista inédito de Gregório de Mattos (Salvador: Edufba, 2000), pp. 13-22. 
suponerlo que la voluntad noveladora de algunos críticos, reacios a admitir que un ser humano, poeta o no, sufra bandazos en su forma de pensar y actuar.

No podemos detenernos en una obra que supera los 800 poemas, aunque sí convendrá decir, con palabras de Haroldo de Campos, que está hecha «falando o código mais elaborado da época» (op. cit., p. 64). Matos es, en efecto, un virtuoso de la retórica, y también de la métrica, como puede serlo Quevedo, uno de sus modelos: usa, además de las estrofas normales, sonetos agudos, sonetos con palabras-rima monosilábicas, sonetos-eco, rimas chuscas, versos de cabo roto, ovillejos, redondillas terminadas en endecasílabo, seguidillas, motes con sus correspondientes glosas, muchas dificultosas y casi siempre en espinelas. No conocemos poeta de esos siglos que se le acerque, ni de lejos, en la cantidad de décimas que compuso, ya que, siendo como es su estrofa preferida, suman varios centenares. Por otra parte, cuando le parece oportuno, Matos inventa palabras, lo que no facilita su lectura, o en el seno de cualquier poema injiere una palabra o frase española, casi siempre para enfatizar otra suya -eso sin tener en cuenta los 19 o 20 poemas íntegramente en castellano de que es autor $^{6}$. De vez en cuando se divierte escribiendo en dialecto bahiano textos que hoy nos suenan a chino: "A linha feminina é carimá / Moqueca, pititinga caruru, / Mingau de puba e vinho de cajú / pisado num piláo de Piraguá. I A masculina é um Aricobé / Cuja filha Cobé um branco Pai / Dormiu no promontório de Passé», etc. (p. 640). Otros los denomina él mismo Disparates na língua brazílica; escuchemos uno en perfecta espinela también de desinencias agudas: "Minha rica Cumari, I minha bela Camboatá / como assim de Pirajá / me desprezas tapiti: / não vedes que murici / sou desses olhos timbó / amante mais que um cipó / desprezado Inhapupê, / pois se eu fora Zabelê / vos mandara un Miraró» (p. 864). Apenas se entiende nada, pero tiene su gracia.

$\mathrm{Al}$ iniciarse la resurrección de Matos, los eruditos no solo tuvieron ocasión de horrorizarse por el contenido escatológico o pornográfico de sus poemas, sino también por el desparpajo con que se apropiaba de obras ajenas, lo que le hizo ser acusado de plagiario desde el primer momento: es la hoy llamada cuestión gregoriana. Matos en vida fue objeto de una sátira que el epígrafe achaca a una pessoa de auctoridade, quien la publicó a nombre del vicario Lourenço Ribeyro (p. 595): "Hoje a Musa me provoca / a que bem pelo miudo I nada cale e diga tudo / quanto me vier à boca». Son décimas cuyo estribillo (mas náo o saiba ninguem) recuerda vagamente el de una letrilla atribuida a Góngora (mas no quiero murmurar, CVIII en la ed. Jammes) o el de otra de Quevedo (mas no ha de salir de aqui, Bl., núm. 651). La estrofa 12a dice: "Mui contente, e muito ledo / mostra que não tem mais trato / do que arranhar como gato / no Parnaso de Quevedo: / traz o mundo em um enredo / com sátiras tão malditas, / que achando-as em livro escritas / se admiram todos que as vêem, I mas não o saiba ninguem». El Parnaso, como es sabido, se publicó por

6. João Carlos Teixeira Gomes enumera la mayoría de ellas en su libro Gregório de Matos, o Boca de Brasa (Petrópolis RJ: Vozes, 1985), p. 327; en la página siguiente, gran cantidad de términos portugueses inusitados. 
primera vez en 1648, y Matos, poco después estudiante en Coímbra, habrá adquirido ese volumen, como también las Obras de Góngora en cualquiera de las ediciones que se venían imprimiendo desde 1633; recuérdese que la última del s. XVII se hizo precisamente en Lisboa, cuando allí vivía Matos (1667). A la acusación replicó el poeta con la letrilla "Um branco muito encolhido" (p. 600), cuyo estribillo (milagres de Brasil sáo) es claro eco de milagros de corte son, perteneciente a la letrilla "Que tenga el engańo asiento" atribuida a Góngora por Hozes y Vicuña ${ }^{7}$ Y a esta respondió el vicario con otra larga e ingeniosa que en las estrofas $1^{\mathrm{a}}$ y $3^{\mathrm{a}}$ acusa a Matos de plagiar a Quevedo y a Góngora: "Doutor Gregório Guadanha, / pirata do verso alheio, / caco que o mundo tem cheio / do que de Quevedo apanha»... "O soneto que mandaste / ao Arcebispo elegante / é do Góngora ao Infante / Cardeal, e o furtaste» (p. 603). El soneto en cuestión, «Subi a púrpura já, raio lucente» (p. 197), es, en efecto, trasposición de «Purpúreo creced, rayo luciente», compuesto por Góngora en 1620; la única rima que varía es la de los vv. 10 y 13. Naturalmente, el juego del segundo cuarteto con las coronas papales y reales no puede mantenerse, ya que el arzobispo de Salvador no es hijo de rey como el Cardenal Infante, lo que obliga a Matos a hacer equilibrios. Pasemos deprisa sobre otros textos señalados en tiempos recientes: «Sacro pastor da América florida» (p. 210), que funde dos sonetos de Góngora: en los cuartetos, "Sacro pastor de pueblos que en florida» (a don Sancho Dávila, obispo de Jaén, 1608); en los tercetos, «Árbol de cuyos ramos fortunados» (a don Cristóbal de Moura, 1593). Matos se ciñe muy al pie de la letra en la imitación del primero, mientras que varía el segundo sin hacer caso de la correlación gongorina entre los versos de los tercetos - un recurso sin precedentes que, como señalamos alguna vez, es lo más original del poema. Otros dos sonetos de Matos derivan del gongorino "Ilustre y hermosísima María». El primero, "Discreta e fermosíssima Maria» (p. 507), toma en cambio su v. 14 de «Mientras por competir con tu cabello». El segundo, de íncipit igual que el anterior, insiste en el carpe diem sin mezcla alguna. "Um vendelhão baixo e vil» es una sátira de estados inspirada en «Un buhonero ha empleado» de Góngora (1593), cuyo estribillo varía en forma creciente de una a diez higas. La de Matos va desde um corno hasta mil cornos, porque así dice el estribillo en la undécima estrofa. La diferencia formal es que las mudanzas de Góngora cuentan seis versos, mientras que las de Matos, ocho.

Los poetas de entonces leían, copiaban, memorizaban y escribían. Matos parece, y así se le ha llamado, «el Quevedo del Brasil», pues, en efecto, es ingenioso, lenguaraz, verborreico, antisemita y en el fondo conservador, como al fin hombre de leyes. Por su cabeza circulan versos, conceptos, poemas, a la espera de que la ocasión los llame. Aquí, como suele ocurrir, los íncipits sirven de poco, porque incluso cuando coinciden o son similares, pueden ser

7. No es por tanto un descuido de João Ribeiro, como cree Teixeira Gomes (op. cit., p. 58), atribuir a Góngora un poema que él, siguiendo a Astrana, cree perteneciente al entremés $E l$ zurdo alanceador (o Los enfadosos) de Quevedo. Al menos en la ed. de J. M. Blecua no figura (Quevedo, Obra poética, IV, Madrid: Castalia, 1981, pp. 123-132). 
simples puntos de arranque. "Estamos na cristiandade? / Sofrer se há isto em Argel?» (p. 651) es el comienzo de unas décimas en que cualquier mediano lector de Quevedo reconoce el romance «¿Estamos entre cristianos? / ¿Sufrirase en Argel esto?» (Bl., núm. 725). Pues bien, aparte las diferencias métricas, los poemas nada más tienen en común: el de Matos es anticlerical, el de Quevedo son protestas de un galán a quien achacan un estupro. Unos tercetos satíricos de Matos comienzan: "Eu sou aquele que os passados anos / cantei na minha lira maldizente / torpezas do Brasil, vícios e enganos». Y así prosigue hasta que en la estrofa séptima vienen a su pluma unos versos de Quevedo en trance similar: "De que pode servir calar quem cala? / Nunca se ha de falar o que se sente? / Sempre se ha-de sentir o que se fala?» Se trata de un homenaje a lo que está bien dicho, traído a cuenta por razones de forma e intención: el pasaje evocado es también un terceto, de una epístola igualmente censoria. Se localizó la fuente, menos visible, del soneto "Oh que cansado trago o sofrimento» (p. 760), cuyos tercetos reflejan los del soneto quevediano "Los que ciego me ven de haber llorado" (Bl., núm. 444). Este es un poema petrarquista; Matos en el suyo, como aclara el epígrafe, se duele de su poca suerte en general; la concordancia de formas no implica la de los contenidos. En otras ocasiones Matos tiene buen cuidado de soltar indicios que facilitan la identificación: «Oh não te espantes, não, dom Antonio» (p. 139) es una canción burlesca sobre el gobernador António de Souza Meneses (1682?), llamado Braço de Prata por haber suplido con él su manquedad. La diástole [Antonio] por António, junto con la raíz de espantar, nos lleva a la fuente: «No os espantéis, señora Notomía», canción de Quevedo en burla de una mujer flaca (Bl., núm. 620). Si las dos primeras estrofas vierten el poema castellano, las 16 restantes se apartan de él por completo, aun riéndose de un personaje poco recomendable ${ }^{8}$. Nadie parece haber señalado el romance "Preso entre quatro paredes / me tem Sua Senhoria», enderezado contra el mismo gobernador, porque ni sus palabras iniciales ni su asonancia son reconocibles; sí, en cambio, la idea, que remite a la jácara también quevediana «Zampuzado en un banasto / me tiene Su Majestad» (Bl., núm. 856). Sin embargo, hay que esperar 56 versos hasta que aparece este pasaje: "Todo este mundo é prisão, I todo penas e agonias, I até o dinheiro está preso / em um saco que o oprima. I A pipa é prisão do vinho, / e da água fugitiva / (sendo tão leve, ligeira) / é prisáo qualquer quartinha. I Os muros de pedra e cal / são prisáo de qualquer vila, I da alma é prisáo o corpo, I do corpo é qualquer almilha...", etc., que vierten, con poca variación, un curioso pasaje lírico de la jácara original: «Todo este mundo es prisiones, / todo es cárcel y penar: / los dineros están presos / en la bolsa donde están; / la cuba es cárcel del vino, / la troj es cárcel del pan, / la cáscara, de las frutas, / y la espina, del rosal. / Las cercas y las murallas / cárcel son de la ciudad; / el cuerpo es cárcel de l'alma, / y de la tierra la mar...» (vv. 81-92). Estos últimos versos muestran bien el proceso: Quevedo, con toda lógica, afirma que «el cuerpo es cárcel del alma, / y de la tierra, la mar».

8. En el citado libro de Teixeira Gomes, pp. 64-72, pueden verse otros poemas de Quevedo imitados más o menos de cerca por Gregório de Matos; ejemplos dudosos en pp. 76-82. 
Matos lo reescribe así: "Da alma é prisão o corpo...» -y ahora viene lo nuevo- I «...do corpo é qualquer almilha», es decir, 'del cuerpo es prisión cualquier camisa', con el políptoton alma / almilha, ausente del modelo. La imagen quevedesca del mar como prisión de la tierra («y de la tierra la mar; / del mar es cárcel la orilla...») se pospone a la siguiente copla, omitiendo lo concerniente a la orilla y anticipando muy cambiados los versos que hablan de la mina: «o mar éprisão da terra, I a terra é prisão das minas». Este último resume el díptico de Quevedo: "preso está el oro en la mina, / preso el diamante en Ceilán». Aquí se ve bien la diferencia entre recreación y plagio, y al mismo tiempo se pone de relieve hasta qué punto Matos tenía interiorizada la poesía de los maestros castellanos, pues evoca el pasaje más certero en el momento adecuado.

El soneto "Vieram os Flamengos e o padrinho» habla de una fiesta de bautizo, a la que acuden varios extranjeros con un barril de vino, y que acabó estropeada por la lluvia (p. 1129). Matos recuerda un soneto de Quevedo sobre unos franceses buenos bebedores que visitaron la corte: «Vino el francés con botas de camino / y sed de ver las glorias de Castilla, / y la corte, del mundo maravilla, / le salió a recibir como convino» (Bl., núm. 565, de 1612); esta disociación insinuada la recoge el brasileño en su segundo cuarteto: «Porque não sendo as botas de caminho, I corriam pela praia a todo o trote: / foi ali hospedado dom Bribote / como convinha não, como com vinho». Una sátira contra ladrones, «Ontem, Nise, a prima noite / vi sobre o voso telhado» (p. 355), evoca el romance "Debe de haber ocho días, / Aminta, que en tu tejado", de Quevedo, quien lo tituló Consultación de gatos (Bl., núm. 750). Este, y el titulado Conversación de las mulas de unos médicos con la haca de un barbero (Bl., núm. 735), a su vez proceden del romance «Murmuraban los rocines» de Góngora, de 1593, impreso en el Romancero general. Cuando llega el turno a un gato del primer romance cuyo amo es alguacil, dice que le hace ayunar «porque em casa de un meirinho / nas suas arcas e armários / é quaresma toda a vida / e témporas todo o ano». El pasaje es de Quevedo, sí, pero en esta última frase se reconoce bien el v. 20 del romance gongorino "Aunque entiendo poco griego» al describir la casa de Leandro: "cernícalos de uñas negras / en las almenas criados: / muchos dones a un candil / y témporas todo el año».

El caso más aparente de imitación próxima es el del soneto castellano «Una, dos, tres estrellas, veinte, ciento» (p. 767), cuyo primer cuarteto reproduce el homónimo del conde de Salinas, muy difundido pero no impreso hasta 1706. En cambio, las demás estrofas nada tienen que ver, si se exceptúa el símil que gobierna el soneto. Edward Glaser, al anotar la versión de Salinas en el ms. 3992 BNE, copia el texto de Matos según la ed. Peixoto, donde lleva el siguiente epígrafe: Haziendo un sojeto la quadra primera del seguinte Soneto, el Autor lo concluio hasta la fin'. James Amado, suponemos, transcribe el del códice Pereira Rabelo: Compara suas penas com as estrellas muy satisfeyto com a nobreza do simile. A primeyra quarta não hé sua.

9. The Cancionero "Manuel de Faria», ed. de Edward Glaser (Münster Westfalen: Aschendorffsche Verlagsbuchhandlung, 1968), p. 216. 
Por tanto, al menos en dos ocasiones Matos advierte que el primer cuarteto no le pertenece, forma de actuar nada propia de un plagiario; es la misma de Góngora en «Guerra me hacen dos cuidados» (1619), que Chacón anota así: La redondilla es ajena, y pidiéronle la continuase en una décima. Otra vez, al frente del soneto «Senhora Mariana, em que vos pes» (p. 657), Matos puso esta frase: imitando a $\boldsymbol{D}$. Thomaz de Noronha, poeta entonces inédito. De igual manera, en el poema a Dionizio de Avila Barreyro (p. 311), que consta de 30 octavas cada una de ellas terminada con un verso de Camóes, tuvo buen cuidado de poner al margen la abreviatura Cam. otras tantas veces.

João Carlos Teixeira Gomes, en su libro antes citado, dedica el primer capítulo a resumir los cargos de plagiario que hicieron a Matos modernamente Gregório Varnhagen, João Ribeiro, Sílvio Júlio y Paulo Rónai, analizando poemas de Góngora y Quevedo, o a ellos atribuidos, que fueron parafraseados, utilizados o «saqueados» por Gregório de Matos. En el capítulo siguiente estudia la imitación desde Aristóteles y Horacio hasta nuestros días, deteniéndose en el concepto de intertextualidad, que invalida o rebaja mucho tales censuras. Por su parte, Sílvia La Regina ha elaborado una lista de detractores y defensores de Matos; entre los últimos, además de ella misma, están Segismundo Spina, Wilson Martins, Augusto y Haroldo de Campos, y el propio Teixeira Gomes:

Os dois últimos - dice La Regina-comprovaram, por vias diferentes, como Gregório, longe de ser um banal imitador de obras alheias, se inserisse perfeitamente na cultura e no gusto barroco, numa linha de tradição criativa que vinha desde a antigüidade clásica e na qual o verdadeiro artista atuava num rebuscado processo de intertextualidade e recreação, ou tambem processo antropofágico ante litteram. ${ }^{10}$

Nosotros, en lugar de perder el tiempo en rebatir las acusaciones, nos limitaremos a recordar que Haroldo de Campos, al defender la dignidad de la traducción como categoría de la creación, se pregunta cómo puede ser plagiario un poeta por haber «traduzido para o português o intrincado labirinto gongorino, quando um dos brasóes de glória de Ungaretti é ter feito coisa semelhante para o italiano» (op. cit., p. 86). A eso el crítico podía haber añadido un argumento de cierto peso: Góngora hizo otro tanto con los poetas italianos que vertió en sus sonetos juveniles, sin tampoco mencionar a sus autores ${ }^{11}$. La única diferencia, si se quiere, es el salto cualitativo resultante, cosa opinable. No es lo mismo

10. Fernando da Rocha Peres \& Silvia La Regina, Um códice setecentista inédito de Gregório de Mattos, cit., pp. 29-30.

11. Véanse al respecto las certeras palabras de Andrés Sánchez Robayna, que, mutatis mutandis, pueden trasponerse a Matos: «En todas estas composiciones Góngora hizo una suerte de traducción libre o creativa de los originales italianos: no se ciñó a la literalidad del texto de origen, sino que creó un nuevo poema en español a partir de un original en otra lengua... Si el propio Góngora aprendió de esta manera a asimilar una tradición poética, y a hacerlo no de manera servil, sino creadora, intentando ante todo escribir poemas en su lengua, es evidente que la traducción como escuela, como aprendizaje, ha probado de sobra su eficacia» (¿Qué podemos aprender hoy de Góngora?, Salamanca: Seminario de Estudios Medievales y Renacentistas, 2017, pp. 19-20). 
«superar» a Bembo o a Bernardo Tasso que a Góngora. Pero aquí el verbo es inadecuado: se trata más bien de «hombrear».

Ya hemos dicho que semejante querella no nos interesa ahora, sino completar el inventario de estilemas gongorinos que permitan analizar los grados y formas de su aprovechamiento por Matos ${ }^{12}$. En las páginas anteriores hemos aducido ejemplos varios, casi todos ya señalados, porque interesaba considerarlos para percibir el modus operandi de la imitación gregoriana. Los que siguen son los restantes que hemos detectado. Matos, en sus treinta años de vida en Portugal, cómodamente instalado como juez en Alcácer do Sal o en Lisboa, tuvo tiempo de rumiar no solo la obra de Góngora, Quevedo o Villamediana, sino también la de sus secuaces portugueses, aunque estuviesen inéditos, pues no hay duda de que la obra, por ejemplo, de un colega de magistratura como Barbosa Bacelar, o de un autor tan inclinado a la sátira como António de Noronha, muerto al poco de llegar Matos a Portugal, circuló con amplitud en manuscrito. De hecho, a nuestro juicio, este último poeta, aun hoy mal conocido, es un eslabón fundamental entre los maestros castellanos y el poeta brasileño, y no faltan los poemas cuya atribución comparte con Matos.

El soneto "Pequéi, Senhor, mas não porque hei pecado» (p. 69) tiene muy poco o nada de gongorino, y no sabemos dónde habrá leído Matos su original español considerado fuente segura ${ }^{13}$. Curiosamente, según aclara Robert Jammes ${ }^{14}$, aparece a nombre de Góngora en el ms. F.IV.33 de la biblioteca de El Escorial, de nula autoridad, pero cuyo colector, al atribuirlo, tuvo sus razones que bien pudieron coincidir con las de Matos. Caso similar será el del soneto que describe la vida estudiantil "Mancebo sem dinheiro, bom barrete», (p. 543) cuyo verso final resume: "Pouco estudo; isto é ser estudante». El modelo es «Bolsa sin alma, perezoso arriero», que se asigna a Góngora en el ms. 3796 BNE, f. 197, y en el ms. Toledo y Godoy, f. $17^{15}$. La letrilla «Que esteja dando o Francés / camoesas ao Romano» (p. 906) es una sátira en 16 décimas con el estribillo: efeitos sáo do cometa, refiriéndose al aparecido en 1686 que alborotó a los sebastianistas. La fórmula que sustantivador + subjuntivo repetida en varias estrofas de una letrilla es muy gongorina desde «Que pida a un galán Minguilla», de 1581, donde se usa más de 40 veces, y reaparece en varias atribuidas; de estas una, "Que tenga el engaño asiento», antes citada como impresa en Hozes y Vicuńa, glosa el estribillo milagros de Corte son, cuyo sentido concuerda con el del cometa. «Suspende o curso, ó Río, retrocido» es un

12. El inventario, aunque incompleto, lo hemos apuntado en nuestro libro Nuevos poemas atribuidos a Góngora (Barcelona: Sirmio, 1994), pp. 235-238.

13. Sin mucha pesquisa, aparece en dos mss. de la BNE, dos del Palacio Real, uno de la Hispanic Society, y está impreso en el Ramillete de divinas flores (Amberes: Cesar Ioachim Trognesius, 1629), p. 101.

14. Études sur l'œuvre poétique de don Luis de Góngora y Argote (Bordeaux: Université, 1967), pp. 238-239.

15. Góngora, Sonetos, ed. de B. Ciplijauskaité (Madison, Wisc., 1981), p. 622. La editora añade que en el ms. 324 de Coimbra, f. 116, una anotación moderna lo atribuye a Gregório de Matos, OC, VI, p. 98, dato que no recoge James Amado. 
soneto de Matos que junto al río Caípe se lamenta porque una señora prefería a otro (p. 426). Habla, pues, de un asunto ajeno a Góngora. Pero como se dirige a un río, Matos no puede menos de evocar el soneto en que Góngora se dirige a un arroyo solo para pedirle que discurra mansamente ( $\mathrm{Oh}$ claro honor del líquido elemento»). La frase del v. 12: "que no es bien que confusamente acoja...", figura en el mismo verso del soneto brasileño: "que não é bem que tuas águas frias...", etc., hecho que, aun siendo poco relevante, sería ingenuo considerarlo casual.

"Daqui, desta Praia grande» (p. 150) es un romance-invectiva contra Bahía en que Matos presenta el contraste entre su vida en Portugal y la que ahora lleva. Está inspirado en el de Góngora "Qué necio que era yo antaño», sobre todo en este pasaje del final: "Faço versos mal limados / a uma moça como um brinco, I que ontem foi alvo dos olhos, / hoje é negro dos sentidos. I Esta é a vida que paso, / e no descanso em que vivo, / me rio dos Reis de Espanha / em seu célebre retiro". Estos versos son trasunto, aunque lejano y con distinta asonancia, de los siguientes: "Discreciones leo a ratos / y necedades respondo / a tres ninfas que en el Tajo / dan al aire trenzas de oro... / Con esto engaño las horas / de los días perezosos, / y vame tanto mejor / cuanto va de cuerdo a loco». Matos vuelve a este romance en sus décimas "Qué nescio que era eu então» (p. 349), cuyo primer verso y su contenido son asimismo próximos del modelo. La sátira «Destes que campam no mundo» (p. 347), contra los avaros, injustos, hipócritas, etc., se inspira en la letrilla gongorina «Ya que rompí las cadenas», de hacia 1590, que divide sus mudanzas en dos semiestrofas terminadas en el doble estribillo: Dios me libre / Dios me guarde; la mayoría comienzan con esta fórmula: de andar... / de dama... / y del mercader... / de doncella... / y del galán..., etc., adoptada por Matos desde el comienzo, como también la bipartición de estrofas con los estribillos: Anjo bento / Deus me guarde. Por si fuera poca la proximidad, la última mudanza toma su materia de "Da bienes fortuna».

«Sobre esta dura penha / que repartida em rocas / contra o mar inimigo / quatro fileiras forma» (p. 754) es un romance de Matos con igual medida y asonancia que el piscatorio de Góngora «Sobre unas altas rocas, / ejemplo de firmeza, / que encuentra noche y día / el mar, estando quedas», de 1601 según Chacón. También coincide el escenario, en que un pescador lamenta sus desdichas amorosas, en forma directa en Góngora, indirecta en Matos. Más vago es el eco gongorino en el romance "Na roça os días passados / vi a senhora Tetê», que conserva la misma asonancia del modelo: «Esperando están la rosa / cuantas contiene un vergel», de $1609^{16}$. Si este es una descripción del palacio de la Primavera, cuya reina es la rosa, el de Matos describe a una moza, convaleciente

16. Imitado también por Manuel Botelho de Oliveira, paisano de Matos, en su romance «Al prado muy de mañana / Anarda sale a un jardín» (Música do Parnasso..., Lisboa: Miguel Manescal, 1705, p. 184). Otro romance suyo, «Por la tarde calurosa / Anarda vino a bañarse, / que eso de echarse a las aguas / es muy del Sol por la tarde» (ibid., p. 177) muestra un eco del gongorino «Nace el niño y, velo a velo, / deja en cabello a su madre, / que esto de dorar las cumbres / es muy del sol cuando nace» (1625). Otro más, «En el tiempo en que la noche» (ibid., p. 204), proviene de «Servía en Orán al rey». 
de una dolencia, a la que hacen venias las demás flores, los pájaros y la fuente. Otro romance gregoriano, "Ao som de uma guitarrilha / que tocava um colomim» (p. 447), describe el baile de unas mulatas recordando el de Góngora a las serranas de Cuenca, fechado en 1603, cuyo estribillo es «iQué bien bailan las serranas! / ¡Qué bien bailan!» En Matos: «Que bem bailam as mulatas, / que bem bailam o Paturi». Asimismo el romance «Eu vi, senhores poetas, / quarta feira pelas três» (p. 791) mantiene igual asonancia que "Guarda corderos, zagala», de Góngora, fechado en 1621. El verso "traidoramente fiel» que hacia el final Matos aplica a la puerta por donde entra una moza recuerda mucho al «undosamente fiel» del romance de Góngora (v. 30), aunque este verso se refiera al agua de un arroyo. Por lo demás, la estructura y los contenidos de ambos romances son del todo dispares. "Os vossos olhos, Vicência, / tão belos como crueis» (p. 852) es un romance de desagravio a una moza a la que en un soneto había aconsejado lavarse los sobacos: «Se são negros vossos olhos, I é já luto que trazeis / pelos homens que habeis morto / a rigores e desdens». El piropo viene directamente del romance gongorino "En dos lucientes estrellas", de 1603, cuya copla final alaba así unos ojos del mismo color: «...Pero no son tan piadosos, / aunque sí lo son, pues vemos / que visten rayos de luto / por cuantas vidas han muerto». El romance "Babu: como ha de ser isto? / Eu já me sinto acaban (p. 572) aparentemente no tiene mayor relación con el de Góngora "iNo me bastaba el peligro / de una grave enfermedad...?» (1593) que la asonancia y el estar dirigido a una moza dura y cruel, pero el final gongorino («...que ella me condena a muerte / y yo me voy a enterrar») deja huella en el de Matos: "Adeus, apertai-me a mão, / que eu já vou a enterrar». En el mismo romance de Góngora se inspira también otro de Matos con distinta asonancia. Compárense estos versos: «Forasteiro descuidado, I se acaso chegar vos move / ou negócio ou pertensäo, / curiosidade ou amores, / guardai-vos, digo mil vezes, I de pôr os olhos nas torres / dessa traidora cidade / que tal basalisco encobren, con estos de Góngora: «Forastero bienvenido / que vais para la ciudad: / si ya os detuviere en ella / o gusto o necesidad, / guardaos, mil veces os digo, / de un basilisco mortal» (vv. 13-18). Todavía la rara endecha gongorina «Moriste, ninfa bella, I en edad floreciente», que lamenta la muerte de dońa Luisa de Cardona en 1594, inspiró a Matos la suya "Morreste, ninfa bela / na florescente idade» (p. 408), hecha en nombre de Vasco de Souza, suponemos, por alguna hija difunta. La inversión de palabras en el último verso permite variar en asonancia distinta la consonancia del modelo. Es especialmente cercana la imitación de los vv. 5-12: «Moriste, y Amor luego / rompió el arco, impaciente, / casto Amor, no el que tira / flechas de oro luciente. / Ninguno hay en la selva / que tu fin no lamente, / o sátiro sea duro / o virgen inocente», que en Matos suenan así: "Morreste, e logo Amor / quebrou arco e carcases; / que muito, se lhe faltas, / que logo se desarme? I Ninguém há neste monte, I ninguém naquele vale, I ou cortesão discreto / ou pastor ignorante / que teu fim não lamente / dando aos quietos ares / já fúnebres endechas, / já trágicos romances». Por si fuera poco esto, aun los vv. 43-44 presentan una reminiscencia del Polifemo al hablar de las aves que no 
se refugian en los cipreses "porque gemendo tristes / andam voando graves». Unas décimas de carácter muy opuesto al poema anterior, las que comienzan «Vendo tal desenvoltura» (p. 929), tras describir la pendencia del mulato Quiringa con un moro en la prisión donde se encontraba el poeta, terminan con estos versos: "Pôs-se em pé o belhacão, I recebendo as alabanças, / e eu entre tantas mudanças / à guitarra lhe cantei: / Serviu na moxinga a El-Rei / um Quiringa con dos lanças", donde moxinga significa 'paliza'. Como salta a la vista, Góngora es tan bueno para un roto como para un descosido.

La mejor sátira de estados debida a Matos, y la más extensa, pues alcanza las 106 estrofas, es "Que ande o mundo mascarado" (p. 371), con estribillo alternante: Boa história / Boa asneira. Es también la más seria y convencional, sobre todo en lo que atañe al clero, la justicia y los casamientos. Su estrofa 31 arremete contra los culteranos, la 104 se ríe del propio poeta. En la 48 aparece esto: "Mas que outros mil à porfia / por toda a vida o dinheiro / ajuntem, que seu herdeiro / ha de gastar num só dia... / boa asneira". Concuerda con los vv. 115120 de "Que pida a un galán Minguilla»: "Que junte un rico avariento / los doblones ciento a ciento, / bien puede ser; / mas que el sucesor gentil / no los gaste mil a mil, / no puede sen». La idea acabó por hacerse tópica, o ya lo era, pero la fórmula que + subjuntivo, hace sospechar que la letrilla gongorina una vez más sirve de fuente a Matos. En una sátira hexasilábica, "Como nada vêem / e andam sempre aos tombos» (p. 364), de estribillo más bien obsceno (forro a minha cona), encontramos estos versos: "Verão um alvar / fidalgo tendeiro, / que o pai sapateiro / lhe fez o solan. El concepto por la bisemia de solar viene de la letrilla gongorina «Tres hormas, si no fue un par / fueron la llave maestra / de la pompa que hoy nos muestra / un hidalgo de solar», de 1600, aunque en uno y otro la broma sobre la hidalguía del zapatero proceda de Marcial. Otra letrilla gongorina con presencia en Matos es "Cura que en la vecindad / vive con desenvoltura, / ¿para qué le llaman cura / si es la misma enfermedad?», de 1602. El poema de Matos en décimas ao cura da Sé que era naquelle tempo indroduzido ali por dinbeiro (p. 208) se desenvuelve de esta manera: « $O$ cura a quem toca a cura / de curar esta cidade / cheia a tem de enfermidade / tão mortal, que não tem cura; / dizem que a si só se cura / de uma natural sezão / que lhe dá na ocasião / de ver as moças no eirado, / com que o cura é o curado, / e as moças seu cura são", muestra de habilidad no ya imitatoria sino creativa: una múltiple antanaclasis (que en Góngora era solo doble), más un concepto final por disociación también ausente del modelo. Pero la imitatio se presta a otras filigranas, sobre todo en la estrofa $5^{\mathrm{a}}$, de manera que puede decirse que Matos, impulsado por el mote castellano, se convierte casi en colaborador de Góngora. Lo prueba también la sátira de estados «Uma cidade tão nobre» (p. 34), que pasa revista a hidalgos, doncellas, casadas, letrados, clérigos, mercaderes, viudas, galanes, reservando la última estrofa para un abad: "Se virdes um dom Abade I sobre o púlpito cioso, I nâo lhe chameis religioso, / chamai-lhe embora de frade: I e se o tal paternidade / rouba as rendas do convento / para acudir ao sustento / da puta, como da peita / com que livra da suspeita / do Geral, do Viso-Rei: / esta é a 
justiça que manda El-Rei». Los ecos son aquí bien perceptibles, ya que las tres estrofas del dechado insisten en lo inexacto que es, a ese tipo de cura, llamarle cura, padre o reverencia. Mucho menos peso tiene la imitación, a pesar del comienzo, en las décimas "Que cantarei eu agora, / senhora dona Talia, / com que todo o mundo ria / do pouco que Jelu chora?: I inspira-me tu, senhora...", etc. (p. 858). Las cinco décimas de Góngora "¿Qué cantaremos ahora, / señora dońa Talía, / con que todo el mundo ría / cuando todo el mundo llora? / Inspirádmelo, señora...», de 1605, se refieren a unas fiestas de Valladolid a las que no asistieron los reyes. Las de Matos se ríen de una mulata maltratada por un sargento. No tienen, pues, en común más que el arranque, dejado tal cual en la imitación porque es insuperable.

Tratamiento aparte requiere la letrilla gongorina «Aprended, Flores, en mí», que Matos debía de saber de memoria. En una sátira al gobernador António Luis Gonçalves da Câmara Coutinho (1690-1694), a quien tacha de homosexual, la segunda décima incrusta el primer verso de su estribillo: «Tomem, pois, exemplo aqui / o Tucano e o Ferreira, / pois lhes diz esta caveira / aprended, flores, de mi" (p. 176). El poema "Isto faz-se à gente honrada?» (p. 287) enfila por segunda vez al capitán Teyxeira de Mendoça poniéndolo de ladrón. Su tercera estrofa comienza: "Outro que anda por aqui / esquecido do que foi / lo que va de ayer a oy / aprender pode de mi», injiriendo así el segundo verso de la cuarteta con mezcla de lenguas. Toda la sección 4a, titulada en la ed. Amado $\boldsymbol{A}$ nossa Sé da Bahia, está dedicada a clérigos, y los poemas en su mayoría son satíricos, como el que empieza "Ao Padre Vigário a flor, I ao pobre Doutor o fruito", en seis décimas (p. 240). La última de ellas es bilingüe, y se las arregla para acomodar los dos versos que faltan de la cuarteta, según se ve en vv. 5-10: «este exemplo lhe gravei, / y este desengaño doy / de la dicha en que me estoy / cantando a su flor ansí, / que ayer maravilla fui / y oy sombra mía aun no soy». Pero la devoción de Matos por esta letrilla va más lejos, pues llegó a forjar esta cabeza derivada de ella: «Ya que flor, mis Flores, fui, / vuestro exemplo aora soy, / pues de flor a Sol subí / y oy de mí aun sombras doy» (p. 413). La nueva cuarteta, impregnada así de esencia gongorina, es objeto de glosa en cuatro décimas también castellanas, en la cuarta de las cuales inserta un verso del original: «lo que va de ayer a hoy, I aprended de un muerto sol». Por último, en otro poema dedicado a la mulata Brásia (p. 1015), le llama Matusalem das flores, imagen que Góngora en su letrilla aplica al girasol.

El soneto «Hoje pó, ontem deidade soberana» (p. 123) lo compuso Matos a la muerte de María Francisca Isabel de Saboya, esposa de los reyes Alfonso VI y Pedro II de Portugal, ocurrida en $1683^{17}$. Se inspira en uno de los epitafios de Góngora a dońa Catalina de la Cerda, duquesa de Lerma, en 1603: «Ayer deidad humana, hoy poca tierra», aunque cambiando las rimas. Sigue de cerca el primer cuarteto (incluso insertando un vocativo en v. 2), y también el segundo, aunque no osa imitar los magistrales recursos del modelo en vv. 7-8: «mortales

17. Al mismo asunto dedicó su primera canción y un soneto Botelho de Oliveira (Música do Parnasso..., pp. 104 y 193). 
señas dieran de mortales: / la razón abra lo que el mármol cierra». Góngora, en el segundo terceto, compara la prócer con una urca, y acaba con una aguda frase de doble sentido: "Si una urca se traga el oceano, / ¿qué espera un bajel luces en la gavia? / Tome tierra, que es tierra el ser humano». Matos extiende la metáfora náutica a los dos suyos sin sacarle aquí mayor fruto. Pero en el soneto al miércoles de ceniza, "Que és terra, homem, e em terra has de tornarte» (p. 78) se acuerda del terceto gongorino antes preterido, y lo vierte así, conservando la bisemia: "Todo o lenho mortal, baixel humano, / se busca a salvação, tome hoje terra, / que a terra de hoje é porto soberano». Ejemplo espléndido de cómo el poeta supo reservar la enseńanza del maestro hasta encontrarle cauce adecuado.

Cambiando de registro, el soneto que descreve a confusão do festejo de entrudo, algo, pues, muy brasileño, "Filhós, fatias, sonhos, mal-assadas" (p. 447), después de una enumeración similar a la gongorina descripción de Madrid «Grandes, más que elefantes y que abadas» (1588), muy difundido e imitado, se cierra con este verso: "Estas a festas são de Santo Entrudo» ${ }^{18}$, que recoge lo antes diseminado, tal como hacía el modelo: «Esta es la corte: buena pro les haga». Lo mismo sucede con el soneto donde Matos descreve o que era realmente naquelle tempo a cidade da Babia de mais enredada por menos confusa: "A cada canto um grande conselheiro / que nos quer governar cabana $e$ vinha» (p. 33); tras enfilar políticos, olleros, mulatos y usureros, termina: $E E$ eis aqui a cidade da Bahia». En la misma tónica se mueve el soneto "Um negro magro em sufilié mui justo» (p. 1192), que describe la procesión de miércoles de ceniza en Recife, y será de los últimos poemas de Matos. Termina así: "Atrás um negro, um cego, um mamaluco, / três lotes de rapazes gritadores, / é a procissáo de cinza em Pernambuco».

Hace años, al estudiar el gongorismo de don Francisco Manuel de Melo, le aplicamos el dictado de quevediano gongorino, intentando retrucar el tópico de su amistad con Quevedo ${ }^{19}$. Aun sin eso por medio, la frase quizá le cuadre mejor a Gregório de Matos, ya que, como se ha dicho, Quevedo es por afinidades varias el modelo que sigue con más ahínco. Pero la sombra de Góngora es muy alargada, e incluso alcanza a sus enemigos, como hemos intentado mostrar también en el caso de Quevedo ${ }^{20}$. Matos tiene un oído excelente y una sensibilidad extrema para percibir y paladear todos los matices de la retórica, o del conceptismo complejo, en la obra de Góngora, aunque ni se le pase por las mientes acordarse de las Soledades, poema que también

18. Se atribuye a António Serrão de Castro en la Academia dos Singulares (João Palma Ferreira, Academias literárias dos séculos XVII e XVIII, Lisboa, 1982, p. 129).

19. "Un quevediano gongorino: don Francisco Manuel de Melo», Alain Bègue y Emma Herrán Alonso (eds.), Pictavia aurea. Actas del ix Congreso de la Asociación Internacional «Siglo de Oro» (Toulouse, Presses Universitaires du Mirail, 2013), pp. 11-34.

20. «Presencia de Góngora en la poesía de Quevedo», Joaquín Roses (ed.), El universo de Góngora: orígenes, textos y representaciones (Córdoba: Diputación, 2014), pp. 473-494. 
producía sarpullidos a Quevedo y que no menciona Gracián, a pesar de su devoción por don Luis. El Góngora que atrae más a Matos es el de letrillas, décimas y romances, junto con el de algunos sonetos encomiásticos o satíricos, lo que don Marcelino hubiera llamado el ángel de luz. Por lo demás, no nos engañemos: la obra de Matos imitada de los maestros espańoles no llega, ni con mucho, a la vigésima parte del total, por innegable que sea cuánto pudo aprender de ellos. Un argumento más que añadir a la cuestión gregoriana, si algún sentido tuviera seguir dándole vueltas. 